\title{
Features of Constructing Recrystallization Curves of the 2nd and 3rd Types for High-Alloy Alloys of Various Structural Classes VZH159 and $14 \mathrm{Cr} 17 \mathrm{Ni} 2$
}

\author{
V.V. Galkin ${ }^{1,}{ }^{*}$, P. M. Yavtushenko ${ }^{2}, A . A$. Generalov $^{2}, A . S$. Fomichev $^{2}$ and E.O. Bazhenov ${ }^{1}$ \\ ${ }^{1}$ Nizhny Novgorod State Technical University n.a. R.E. Alekseev (NNSTU), 24 Minina Street, \\ Nizhny Novgorod 603950, Russia \\ ${ }_{2}^{2}$ PJSC "Ruspolimet", 1, Vosstaniya street, Kulebaki, Nizhny Novgorod region, Russia
}

\begin{abstract}
The features of methods for constructing recrystallization curves of the second and third kind and the dependence "average grain size (area) - strain intensity - temperature" are given. For alloys of various structural classes VZH159 and 14Cr17Ni2 using the above methods, a recrystallization curve and the recrystallization dependence for a temperature of $1100^{\circ} \mathrm{C}$ are constructed. The advantages and disadvantages of the above methods are considered.
\end{abstract}

\section{Introduction}

Under conditions of hot deformation at temperatures above 0.4 of the melting point, the recrystallization process occurs in metal materials, which is characterized by the formation of new grains instead of deformed ones. To evaluate the recrystallization process of a hotdeformed material, recrystallization curves of the 2 nd kind are constructed, showing the dependence of the average grain size on the degree and temperature of deformation at a given rate. For the conditions of the final heat treatment, recrystallization curves of the third kind are constructed, in which two curves are given for each temperature: one for the grain size after deformation, the other for the grain size after heat treatment (annealing). These curves have limitations for evaluating the recrystallization process in real technological processes. As a result, in some cases, recrystallization curves are constructed for various deformation schemes [1-3].

The first construction of recrystallization curves in the 20 s of the last century in relation to low-carbon steels was performed by Tafel, Hahnemann and Schneider. For the tests, the method of compression of cylindrical samples with plane-parallel supports was used. The grain size was determined by the intersection of the diagonals of the longitudinal section of the deposited sample (Gein's method) and correlated with the relative deformation of the sample in height. In the future, Siebel and Pump proposed a method that included the sedimentation of samples using conical supports, which, due to the significant unevenness of the deformed state at compression degrees above $50 \%$, was not developed. In the $30 \mathrm{~s}$,

* Corresponding author: galvv21@mail.ru 
the method of Tafel, Hahnemann and Schneider was improved by I. M. Pavlov. The true recrystallization curves were constructed from the actual grain sizes in accordance with the true deformation, which was determined by the change in the thread pitch of the screws. It is worth noting the Korneev method for constructing of recrystallization curves of alloy steels, according to which the maximum grain size was detected in the fourth part of the longitudinal section of the deposited sample over the entire area, which was correlated with the relative decrease in the height of the sample in the diagram. For the construction of recrystallization curves, a method based on the use of flat conical samples deformed by stretching is also used. Deformations are calculated by increasing the distance between adjacent marks applied to the sample [1]. The considered methods of constructing recrystallization curves have disadvantages. First, a large number of tests are required. Secondly, the degree of deformation is used as an indicator of the relative deformation in height, which does not allow us to characterize the deformed state of the material under conditions of complex stressing $[1,4]$.

In previously published works, a method for evaluating the recrystallization process was given, which eliminates the listed shortcomings. The method is based on the application of the dependence in the coordinates "average grain size (area) strain intensity - temperature". For its construction, two tests with reduction rate of $\sim 10$ and $45 \%$ are carried out at each temperature [5].

\section{The methodology of the experiment}

In this article, for comparison, the results of constructing a recrystallization diagram for the temperature of $1100^{\circ} \mathrm{C}$ of the VZH159 nickel alloy in the traditional way (with the lines "after shortening" and "after heat treatment") and steel of the ferritic-martensitic class $14 \mathrm{Cr} 17 \mathrm{Ni} 2$ using the developed method are presented.

To plot the recrystallization curves of the VZH159 nickel alloy, a circular cross-section material obtained by compression on a radial forging machine with subsequent processing on a screw rolling mill was used. Grooves were made on the samples, which were filled with glass enamel. The shortening of the samples at each temperature was carried out with relative degrees of deformation: $5,15,30,40,50,60,70 \%$ with a strain rate of $\varepsilon=$ $(0.1 \div 0.12) \mathrm{s}^{-1}$.

To construct recrystallization curves, the deposited samples were cut by wire electroerosion cutting along the longitudinal axis into two halves. One half was used to make the cut and determine the grain size after shortening (Figure 1).

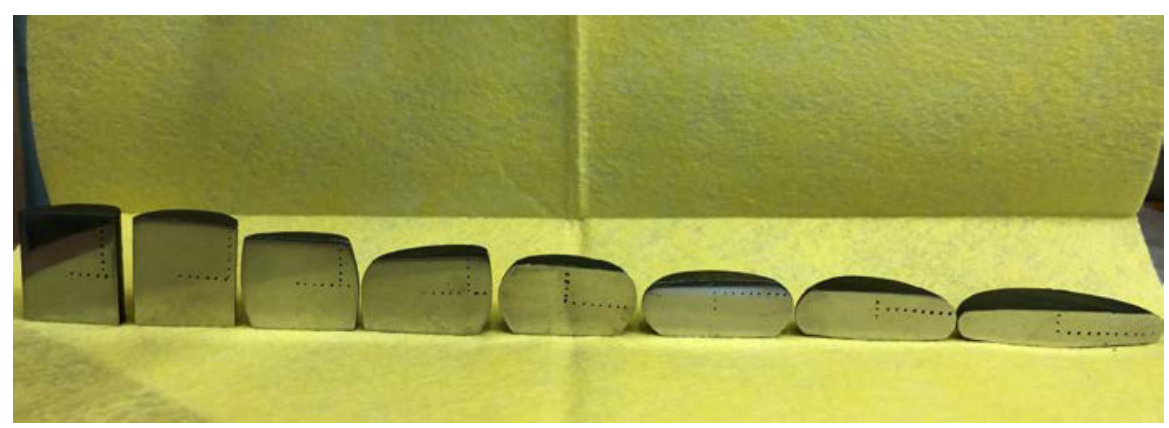

Fig. 1. Photo of cut samples for determining the grain size after shortening

To construct a recrystallization curve with lines "after heat treatment": the second half of the shortenings was cut into samples (Figure 2), which were heated for a duration of 1 
hour and 3 hours. The grain size is determined on the sections made at the ends of the samples, which are mirror-like in relation to the sections "after shortening".

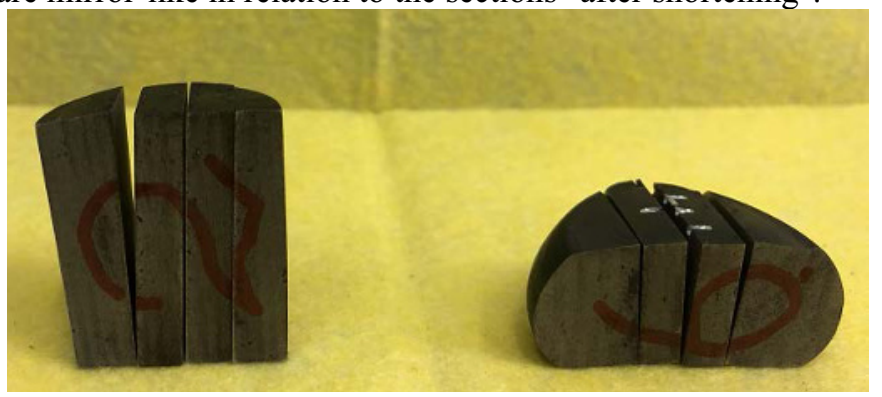

Fig. 2. Photo of the halves of the shortenings cut into samples to determine the grain size after heat treatment

The grain size was determined on microstructural images with an increase of $\times 1000$ with the calculation of the number of grains per unit surface of the section. Based on the results of structural studies, recrystallization curves for the temperature of $1100^{\circ} \mathrm{C}$ with the lines "after shortening" and "after heat treatment" are constructed (Figure 3).

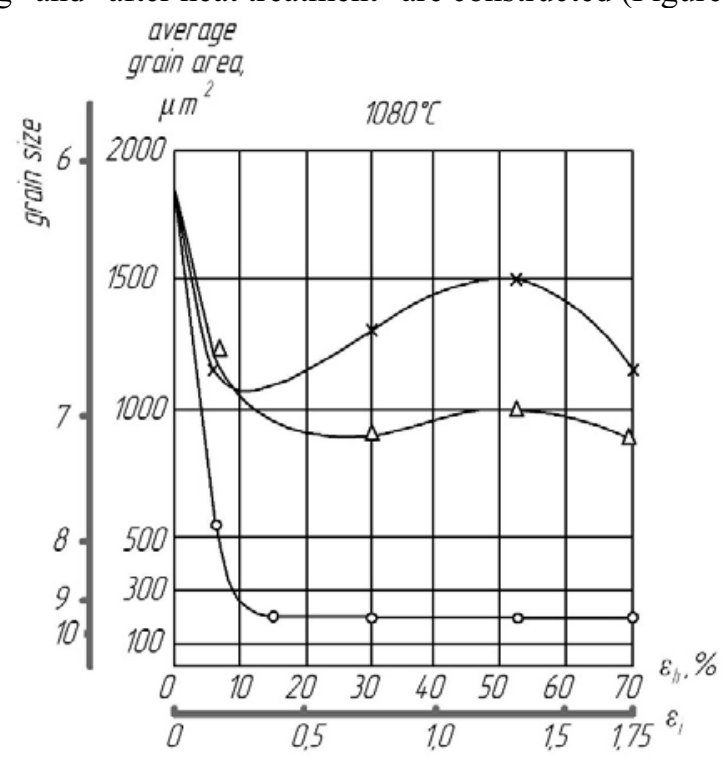

Fig. 3. Recrystallization curve of the III-type alloy VZH159 at a temperature of $1080^{\circ} \mathrm{C}:{ }^{\circ}$ after shortening; $\times$ after shortening and heating ( 1 hour); $\Delta$ after shortening and heating ( 3 hours)

For steel of the ferritic-martensitic class $14 \mathrm{Cr} 17 \mathrm{Ni} 2$, the dependence in the coordinates "average grain size (area) strain intensity - temperature" was constructed on cylindrical samples (diameter $\mathrm{d}_{0}=45 \mathrm{~mm}$, height $\mathrm{h}_{0}=100 \mathrm{~mm}$ ) made of hot-rolled products, the samples were heated in a chamber electric furnace at a temperature of $1100 \pm 10^{\circ} \mathrm{C}$. The shortening of the samples was carried out with compression $\varepsilon_{h}^{1}=12 \%$ and $\varepsilon_{h}^{2}=45 \%$ with a deformation rate $\dot{\varepsilon}=0,2 \mathrm{c}^{-1}$.

The determination of the deformed state in the index of the strain intensity on the longitudinal sections of the deposited samples was performed using the DEFORM software package and simplified solid-state models of tools and workpieces developed in the Solid Works 2007 program. (Figure 4). 


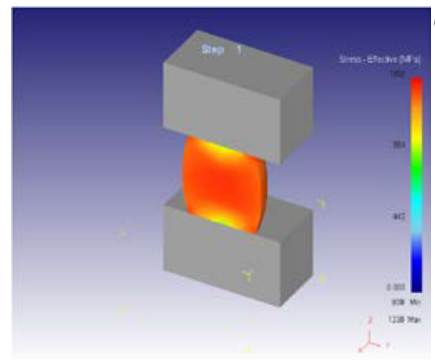

a

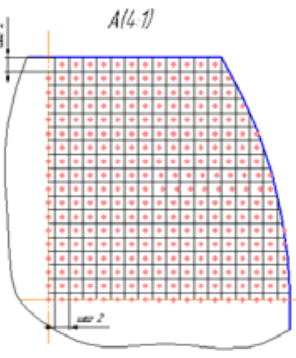

$\mathrm{b}$

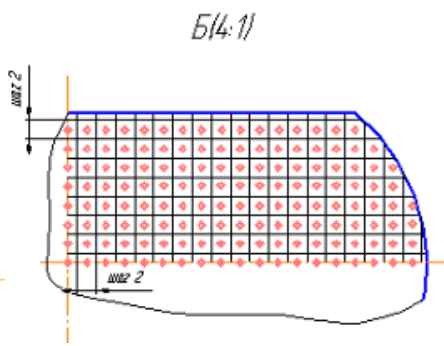

$\mathrm{c}$

Fig. 4. Shortening of a cylindrical sample under plane-parallel supports: a - picture of the deformed state; b, c-coordinate grids with a cell size of $2.0 \mathrm{~mm} \times 2.0 \mathrm{~mm}$ for $1 / 4$ of the longitudinal section of the shortening samples with an average height strain of $12 \%$ and $45 \%$

The strain rate of the material in the longitudinal sections of the samples was determined by reference to the centers of the cells of the coordinate grid with a size of $2.0 \times 2.0 \mathrm{~mm}$.

The reliability of the simulation was confirmed by the correspondence of the sizes of the shortening samples with the sizes of the mathematical models. The deformed state is graphically shown in the form of strain fields in Figure 5.

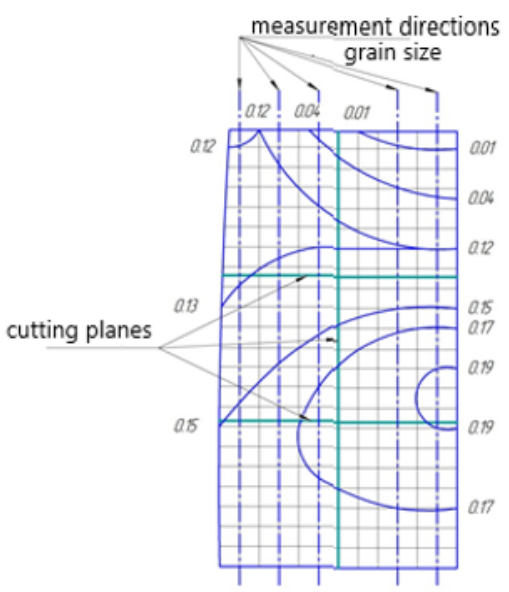

a

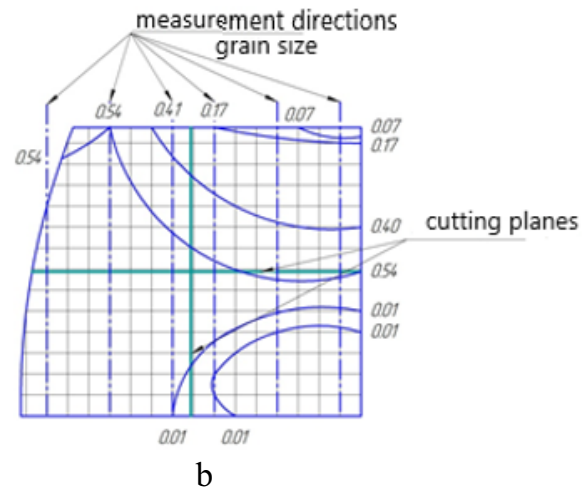

Fig. 5. Deformation fields in the $1 / 4$ part of the longitudinal section of the shortening samples with the degree of deformation: $\mathrm{a}-12 \%, \mathrm{~b}-45 \%$ (the figures are the strain intensity)

Microstructural analysis was performed using the developed computer program [4]. The program, using the principle of binarization (Figure 6), provides monitoring of the microstructure from digital photographs with an increase from 200 to 1000 times, including measurements, determination of the number of grains, their average size and area. 


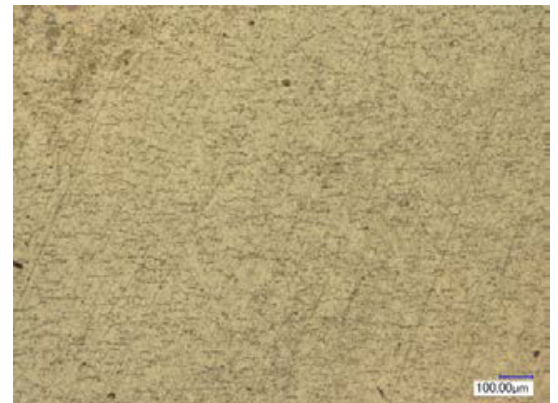

a

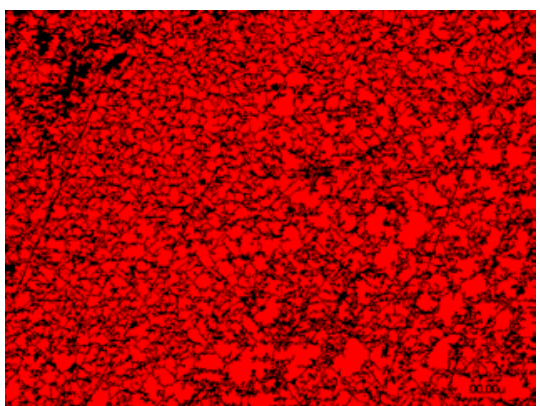

b

Fig. 6. Results of automated processing of the $14 \mathrm{Cr} 17 \mathrm{Ni} 2$ steel microstructure: a-photo of the microstructure; b-binarized image of the microstructure $(\times 200)$

The polished sections were made on samples cut from the shortening blanks. They were cut in height into two equal halves. One of the parts of the shortening sample with a degree of deformation of $12 \%$ was cut: into six samples, with a degree of deformation of $45 \%$ into four samples (Figure 7).

In order of increasing strain intensity, 32 cells are selected. In accordance with their location, the values of the average grain area $\mathrm{S}$ were determined by metallographic method on the polished sections of the longitudinal sections of the deposited samples.

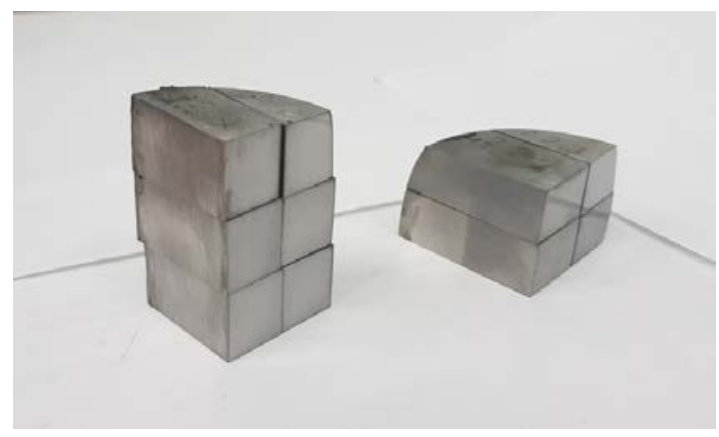

Fig. 7. Photo of the cut $1 / 4$ parts of the shortening samples of steel $14 \mathrm{Cr} 17 \mathrm{Ni} 2$ with degrees of deformation of $12.5 \%$ and $45 \%$

A recrystallization curve is constructed at a temperature of $1100^{\circ} \mathrm{C}$ (Figure 8).

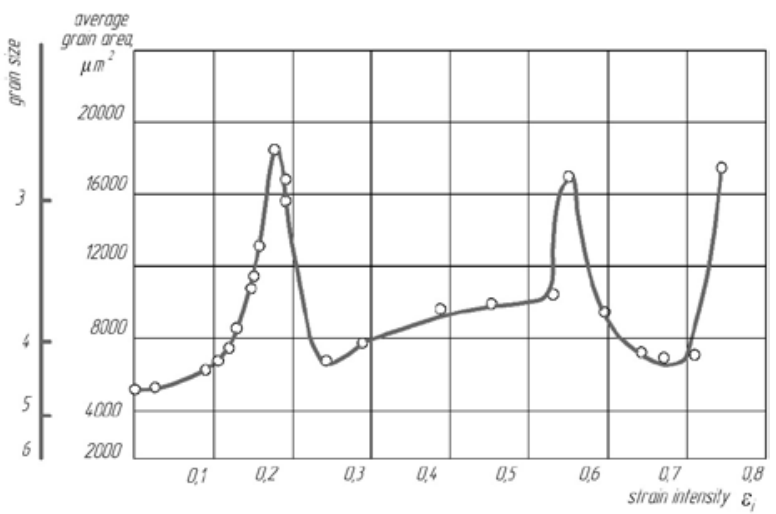

Fig. 8. Recrystallization curve of the 2 nd kind of steel $14 \mathrm{Cr} 17 \mathrm{Ni} 2$ at a temperature of $1100^{\circ} \mathrm{C}$ 


\section{Experimental results and discussion}

The dependence of recrystallization of steel $14 \mathrm{Cr} 17 \mathrm{Ni} 2$ at $1100^{\circ} \mathrm{C}$ is characterized by the presence of three maxima. The first maximum corresponds to the region of small critical values of the degree of deformation and is present in the recrystallization curves of most materials. For steel $14 \mathrm{Cr} 17 \mathrm{Ni} 2$, it appeared in the range of strain intensity values $\varepsilon_{\mathrm{i}}=$ $0,15 \div 0,25$ with an increase in the grain size to a value of $(130-135)$ microns.

The second maximum is located in the region of average degrees of deformation in the range from 20 to $50 \%$. For steel $14 \mathrm{Cr} 17 \mathrm{Ni} 2$, it appeared at the strain intensity $\varepsilon_{\mathrm{i}}=$ $0,53 \div 0,56$. The occurrence of the second maximum depends on the phase composition of the material, the temperature level and the nature of the decomposition of solid solutions, the dissolution and coagulation of dispersed phases (nitrides, carbides, oxides, intermetallides). In the opinion of S. Gorelik "the abrupt increase in grain observed in recrystallization curves, starting from a certain heating temperature, is always the result of the beginning of intensive dissolution of the dispersed phases and can serve as a confirmation of this dissolution" [1].

The third maximum corresponds to the region of high degrees of deformation and occurs when there is a clear deformation texture before recrystallization. For steel $14 \mathrm{X} 17 \mathrm{H} 2$, it appeared at the strain intensity $\varepsilon_{\mathrm{i}}>0,72$.

The analysis of the developed method allowed us to note its features:

- the construction of recrystallization curves is performed with a smooth, rather than a stepwise setting of the degree of deformation, which increases the accuracy of their construction;

- the dependences of recrystallization are constructed in the index of the strain intensity, which provides an assessment of the process of recrystallization of the material under conditions of complex stressing;

- the developed method can be used to construct dependencies after heat treatment [4], since the surfaces of the polished sections of the deformed and heat-treated material have the same cutting surface;

- the method has a great visibility and allows us to assess the degree and nature of the microstructure's heterogeneity in the long term.

\section{Conclusion}

When comparing the method of constructing recrystallization curves of the second and third kind, used in the practice of metal science, and the developed method of constructing the dependence in the coordinates "average grain size (area) - strain intensity-temperature", it is possible to note the advantages of the latter. The developed method allows us to evaluate the recrystallization process under complex stressing conditions, regardless of the deformation scheme, and also requires a smaller number of shortening tests when constructing the dependence.

The work was performed at the NSTU named after R. E. Alekseev under the Agreement with PJSC "Ruspolimet" dated September 20, 2019 No. 19/2504/83-04/1075/19 with the financial support of the state represented by the Ministry of Science and Higher Education of the Russian Federation under the agreement dated December 18, 2019 No. 075-11-2019-084 (state contract ID 0000000007519SZB0002).

\section{References}

1. S. S Gorelik, Recrystallization of metals and alloys (NUST MISIS, Moscow, 2005) 
2. R. W. Cahn Physical metallurgy. 4 edition, Vol. VII, (1986)

3. F. Hesner, Recrystallization of metallic materials (Stuttgart, 1978)

4. E. I. Semenov et al. Forging and stamping (Mashinostroenie, Moscow, 1985)

5. Galkin V. V. On the development of the problem of constructing curves of metal recrystallization, Procurement production in mechanical engineering. 3 (2013) 